\title{
MICHEL JEANNERET, Perpetuum mobile. Métamorphoses des corps et des œuvres de Vinci à Montaigne
}

\section{Michele Mastroianni}

\section{(2) OpenEdition}

\section{Journals}

\section{Edizione digitale}

URL: http://journals.openedition.org/studifrancesi/16260

DOI: 10.4000/studifrancesi. 16260

ISSN: 2427-5856

\section{Editore}

Rosenberg \& Sellier

\section{Edizione cartacea}

Data di pubblicazione: 1 juillet 2019

Paginazione: 144

ISSN: 0039-2944

\section{Notizia bibliografica digitale}

Michele Mastroianni, «michel Jeanneret, Perpetuum mobile. Métamorphoses des corps et des œuvres de Vinci à Montaigne», Studi Francesi [Online], 187 (LXIII | I) | 2019, online dal 01 juin 2019, consultato il 25 janvier 2021. URL: http://journals.openedition.org/studifrancesi/16260 ; DOI: https://doi.org/10.4000/ studifrancesi. 16260

Questo documento è stato generato automaticamente il 25 janvier 2021.

\section{(c) $($ ) $(9)$}

Studi Francesi è distribuita con Licenza Creative Commons Attribuzione - Non commerciale - Non opere derivate 4.0 Internazionale. 


\title{
MICHEL JEANNERET, Perpetuum mobile. Métamorphoses des corps et des œuvres de Vinci à Montaigne
}

\author{
Michele Mastroianni
}

\section{NOTIZIA}

MICHEL JEANNERET, Perpetuum mobile. Métamorphoses des corps et des cuvres de Vinci à Montaigne, Genève, Droz, 2016², 400 pp.

Uscito in prima edizione nel 1997 (Parigi, Macula), il notissimo Perpetuum mobile di Michel Jeanneret viene ripubblicato per le edizioni Droz, ritornando così a essere un volume facilmente reperibile, volume la cui importanza critica, tanto in prospettiva storica quanto in prospettiva ermeneutica, ne ha fatto un testo diventato un classico della letteratura sul Cinquecento. Un classico riproposto in una nuova edizione aggiornata e rivista che acclude un'interessante postface (pp. 385-388) di Michel Jeanneret, scritta nel settembre 2015, in cui l'A. si sofferma sulla prospettiva volutamente seguita nel suo saggio, prospettiva che all'uscita del volume suscitò larga approvazione ma anche dissenso critico («j'ai fait ici un choix délibéré, celui de proposer une image $\mathrm{du} \mathrm{XVI}^{\mathrm{e}}$ siècle moins connue. On a suffisamment parlé de la Renaissance classique, soucieuse d'harmonie et de clarté, de formes fermées et de beauté ideale; on a suffisamment souligné le rôle de la pensée religieuse, éplorée par la fragilité de la créature et l'instabilité d'un monde altéré par la chute, fondée sur une exigence d'ordre et tout orientée vers des certitudes définitives. La sensibilité métaphorique que je découvrais au revers du tableau me paraissait si riche, si puissante et consistante que je lui ai réservé presque toute la place. Au lieu des châteaux de la Loire, on trouve des grottes et des jardins sauvages; plus que du cosmos, je parle du chaos, plus que de la Bible et de Platon, de Pythagore et d'Ovide, et plus que de théologie, de philosophie naturelle. Raphaël cède la place à Vinci, Budé et Calvin 
s'effacent devant Rabelais et Montaigne, comme Scève devant Ronsard. La force bouscule la forme, la variété supplante l'unité, Dionysos occulte Apollon. Pour le dire en termes de chronologie, la Renaissance dont je parle est moins celle du Quattrocento ou de François $I^{\text {er }}$ que celle, plus tardive et plus troublée, de la seconde moitié du $\mathrm{XvI}^{\mathrm{e}}$ siècle. Je m'exposais aussi à la critique, dans les années 1990, en prenant le parti de situer les phénomènes littéraires qui m'intéressaient - la plasticité des œuvres, leur inachèvement - dans un contexte large, où ils voisinent avec les autres arts et dialoguent avec les sciences de la nature - la cosmologie et la biologie, la géologie et la géographie -, avec les théories de l'histoire et celles de la langue, comme la conception de l'homme, et j'en passe. Je me détournais ainsi de deux orhodoxies qui, opposées qu'elles en soient, régnaient sur les études littéraires. D'un côté, le structuralisme nous avait enseigné avec force que le texte fonctionne comme un système autonome ou au cœur d'un réseau intertextuel et sémiotique qui produit du sens par le jeu des relations internes. De l'autre côté, l'histoire littéraire, dans sa version scolaire, répertoriait des auteurs et des œuvres, reconstituait des écoles, des filières, des évolutions, mais en vase clos ou dans une relation sommaire à l'histoire événementielle. J'ai echappé à ce double enfermement et participé au basculement vers une perspective plus ouverte, qui inscrit le littéraire dans un ensemble de paramètres culturels et intellectuels, historiques et anthropologiques. [...]», pp. 388-389).

2 È senza dubbio anche questa postfazione a dare nuovo interesse per uno studio di ampio respiro, sempre fondamentale per una visione critica ed erudita a un tempo sul Rinascimento francese, studio oggi accompagnato da pagine finali in cui da un lato è sottolineata da Janneret un'ideologia critica precisa, dall'altro si evince un atteggiamento di snobismo intellettuale di uno studioso i cui lavori restano imprescindibili per la critica del xvi secolo. 